Disclosure of Interests: None declared

DOI: 10.1136/annrheumdis-2019-eular.6695

\section{THU0351 LOW ERA EXPRESSION MIGHT BE IMPLICATED IN THE DEVELOPMENT OF PULMONARY HYPERTENSION IN FEMALE MICE LACKING PSGL-1}

Rafael González-Tajuelo ${ }^{1}$, María De la Fuente-Fernández ${ }^{1}$, Daniel Morales-Cano², Antonio Muñoz-Callejas ${ }^{1}$, Juan Manuel Serrador ${ }^{3}$, Bianca Barreira ${ }^{4}$, Javier Silván ${ }^{1}$ Carlos Gamallo ${ }^{5}$, Esther Vicente ${ }^{6}$, Santos Castañeda ${ }^{7}$, Francisco Pérez-Vizcaíno ${ }^{4}$, Angel Cogolludo ${ }^{4}$, Ana Urzainqui ${ }^{1} .{ }^{1}$ Instituto de Investigación Sanitaria-Princesa, FIB-Hospital de la Princesa, Inmunología, Madrid, Spain; ${ }^{2}$ University Complutense of Madrid, Instituto de Investigación Sanitaria Gregorio Marañón (IISGM), Pharmacology, Madrid, Spain; ${ }^{3}$ Centro de Biología Molecular "Severo Ochoa" (CBMSO), CSIC-UAM, Cellular Biology and Immunology, Madrid, Spain; ${ }^{4}$ University Complutense of Madrid, Instituto de Investigación Sanitaria Gregorio Marañón (liSGM), Pharmacology, Madrid, Spain; ${ }^{5}$ Instituto de Investigación Sanitaria-Princesa, FIB-Hospital de la Princesa, Inmunología, Madrid, Spain ${ }^{6}$ Instituto de Investigación Sanitaria-Princesa, FIB-Hospital de la Princesa, Rhaumatology, Madrid, Spain; ${ }^{7}$ Instituto de Investigación Sanitaria-Princesa, FIBHospital de la Princesa, Rheumatology, Madrid, Spain

Background: Pulmonary arterial hypertension $(\mathrm{PAH})$ is a rare disease with unknown etiopathogenesis and no curative treatment [1]. $\mathrm{PAH}$ is one of the major complications of connective tissue diseases, and $7-15 \%$ of patients with systemic sclerosis (SSc) develop PAH [2]. Mice deficient for the leukocytic receptor Pselectin glycoprotein ligand-1 (PSGL-1 $\left.1^{-/}\right)$spontaneously develop a SSc-like autoimmune syndrome with ageing [3]

Objectives: To check whether PSGL $1^{-1-}$ mice may develop PAH and the molecu lar mechanisms that might be implicated in the initiation and establishment of the disease.

Methods: Doppler pulse echochardiography was used to evaluate pulmonary artery flow acceleration time/ejection time (PAAT/ET) ratio in WT and PSGL-1 ${ }^{-1}$ $\mathrm{C} 57 \mathrm{BL} / 6$ mice. Isolated pulmonary artery rings were incubated with acetylcholine and responses were registered with a wire myograph coupled to an isometric force transducer. Expression levels of the NO-sensing probe DAR-4M AM by fluorescence microscopy and flow cytometry. Angiotensin II lung concentration was quantified by ELISA. eNOS, p-ENOS, AT1R and AT2R expression was evaluated by western blot. In all cases, data are expressed as the mean \pm SD.

Results: Aged $P S G L-1^{-1}$ females showed reduced flow PAAT/ET ratio indicating $\mathrm{PAH}$. Moreover, pulmonary arterial rings from aged $P S G L-1^{-/}$females presented ROS-independent reduced vasodilation response to acetylcholine. Importantly, eNOS phosphorylation was impaired and NO production by lung EC was reduced in aged $P S G L-1^{-/}$females. Vascular remodeling and reduced expression of AT2R were observed in lungs of $P S G L-1^{-/}$females from a younger age. With ageing, the levels of angiotensin II and the percentages of IFNY-producing interstitial macrophages, $\mathrm{T}$ and $\mathrm{B}$ lymphocytes were increased in $\mathrm{PSGL}-1^{-/}$females. The differences in the gender-biased genotype could be explained by the reduced expression of ER $\alpha$ in the lungs of aged $P S G L-1^{-1}$ females while WT and $P S G L-1^{-1}$ males showed similar expression.

Conclusion: PSGL-1 deficiency leads to pulmonary hypertension in $>18$ months-old female mice, involving various mechanisms:

1. Lung vessel wall remodeling and reduced AT2R expression.

2. Reduced eNOS phosphorylation and reduced NO production with the subsequent specific lung endothelial dysfunction in PSGL $-1^{-/-}$females. Importantly, ROS production is not increased nor help to NO reduction.

3. Increased pulmonary Angll levels with ageing in PSGL $-1^{-1-}$ females.

4. Increased Th1 polarization, reduced Treg population and increased IFN- $\gamma$ production by interstitial macrophages.

Impaired ageing up-regulation of $E R \alpha$ expression in the lungs of PSGL-1/females.

\section{REFERENCES}

[1] Montani et al. Orphanet Journal of Rare Diseases. 2013, 8 (97).

[2] Tedford et al. Circ Heart Fail. 2013, 6 (5): 953-63.

[3] Pérez-Frías et al. Arthritis Rheumatol. 2014, 66 (11): 3178-89.

Disclosure of Interests: Rafael González-Tajuelo: None declared, María De la Fuente-Fernández: None declared, Daniel Morales-Cano: None declared, Antonio Muñoz-Callejas: None declared, Juan Manuel Serrador: None declared, Bianca Barreira: None declared, Javier Silván: None declared, Carlos Gamallo: None declared, Esther Vicente: None declared, Santos Castañeda Consultant for: Amgen, BMS, Pfizer, Lilly, MSD, Roche, Sanofi, UCB, Francisco Pérez-Vizcaíno: None declared, Angel Cogolludo: None declared, Ana Urzainqui: None declared

DOI: 10.1136/annrheumdis-2019-eular.2813

\section{THU0352 \\ THE ROLE OF PRURITOGENIC MEDIATORS IN DERMATOMYOSITIS RELATED ITCH}

Anett Vincze $^{1}$, Erika Herczeg-Lisztes ${ }^{2}$, Katalin Szabó ${ }^{1}$, Melinda Nagy-Vincze ${ }^{1}$, Tamás Bíró ${ }^{3}$, Katalin Dankó ${ }^{1}$, István Balázs Tóth ${ }^{2}$, Zoltán Griger ${ }^{1}{ }^{1}$ Faculty of Medicine, University of Debrecen, Division of Clinical Immunology, Department of Internal Medicine, Debrecen, Hungary, ${ }^{2}$ Faculty of Medicine, University of Debrecen, Department of Physiology, Debrecen, Hungary; ${ }^{3}$ Faculty of Medicine, University of Debrecen, Department of Immunology, Debrecen, Hungary

Background: Pruritus is a common symptom in systemic autoimmune dis eases like dermatomyositis (DM). Recent researches have indicated that interleukin-31 (IL-31), IL-33, IL-6, or inflammatory cytokines, such as tumor necrosis factor $(\mathrm{TNF} \alpha)$, peroxisome proliferator-activated receptor $\gamma$ (PPAR $\gamma$ ) and ion channels belonging to the transient receptor potential (TRP) family are involved in pruriception.

Objectives: We examined targeted gene expression analysis of lesiona versus non-lesional skin samples of patients affected with active DM. We looked for correlations between the examined pruriceptive signaling molecules, disease activity and itching sensation of DM patients.

Methods: Gene expression of TNF $\alpha$, PPAR $\gamma$, IL-33, IL-6 and TRPV channels in lesional DM skin was evaluated by RT-qPCR and was compared with non-lesional DM skin samples. Pruritus and disease activity of DM was evaluated by the 5 -d itch scale and Cutaneous Dermatomyositis Disease Area and Severity Index (CDASI), respectively. Statistical analysis was performed with IBM SPSS 20.0 software.

Results: Skin samples of 17 active DM patients were analyzed. We could show, that itching index in DM was positively correlated with CDASI score with a correlation coefficient of $0.82(p<0.001)$. TNF $\alpha$ gene expression was significantly higher $(34.87 \%)$ in lesional DM skin than non-lesional DM skin $(p=0.03)$. The normalized TNF $\alpha$ mRNA expression was positively correlated with itch scale $(R=0.605, p=0.022)$ and its level was significantly higher in skin samples of patients with severe itch (itching score: 15-20) versus mild itch (itching score: $5-10)(2.02 \pm 0.38$ vs. $1.12 \pm 0.20 ; p<0.01)$. The level of PPAR $\gamma$ was decreased in lesional DM skin, but this was statistically not significant. The mRNA expression of normalized PPAR $\gamma$ was negatively correlated with itch scale $(R=-0.618, p=0.019)$, and its level was significantly lower in skin samples of patients with severe itch versus mild itch $(0.28 \pm 0.36$ vs. $1.53 \pm 0.98 ; p=0.038)$. Lesional IL-6 mRNA levels were associated with CDASI activity score $(R=0.619, p=0.018)$. The mRNA levels of TRPV1-4 channels were not associated with 5-D itch score, but normalized TRPV1 and TRPV4 mRNA expressions were positively correlated with CDASI damage score ( $R=0.699, p=0.008 ; R=0.789, p=0.001)$. Interestingly itching sensation of DM patients was not correlated with IL-33 mRNA levels measured in skin samples.

Conclusion: Our results argue for that higher cutaneous disease activity generate pruritus. TNF $\alpha$ and PPAR $\gamma$ might play a determining, but opposite role in DM-associated itch. Furthermore IL-6, TRPV1 and TRPV4 channels might participate in pathomechanism of cutaneous manifestation of the disease.

\section{DISCLOSURE OF INTERESTS: :}

None declared

DOI: 10.1136/annrheumdis-2019-eular.3116

\section{THU0353 AN ORALLY AVAILABLE HIGHLY SELECTIVE 5- HYDROXYTRYPTAMINE 2B (5-HT2B) RECEPTOR ANTAGONIST AMELIORATING PULMONARY AND DERMAL FIBROSIS IN PRECLINICAL MODELS OF SYSTEMIC SCLEROSIS}

Christina Wenglén, Helena Arozenius, Lars Pettersson, Gunilla Ekstrom. AnaMar $A B$, Medicon Village $A B$, Lund, Sweden

Background: Serotonin or 5-hydroxytryptamine (5-HT) is well known as a stimulator of tissue fibrosis and a significant role of peripheral $5-\mathrm{HT}_{2 \mathrm{~B}}$ receptors in fibrosis has been suggested with the receptor being upregulated in fibrotic tissues. In addition, agonism of the $5-\mathrm{HT}_{2 \mathrm{~B}}$ receptor has been implicated in human tissue fibrosis caused by drugs known to activate the receptor. Pharmacologic inhibition of $5-\mathrm{HT}_{2 \mathrm{~B}}$ receptor signalling consequently represents a promising treatment strategy for fibrotic disorders including systemic sclerosis. 5-HT is released from platelets activated upon vascular damage, one of the first pathological events in systemic sclerosis. The local $5-\mathrm{HT}$ concentration is increased and leads to activation of $5-\mathrm{HT}_{2 \mathrm{~B}}$ receptors on e.g. fibroblasts. The pro-fibrotic effects of $5-\mathrm{HT}$ and the $5-\mathrm{HT}_{2 \mathrm{~B}}$ receptor are believed to be mediated through activation of the TGF- $\beta$ Smad signaling pathway.

Objectives: The objective of the present study was to evaluate a nove highly selective orally available $5-\mathrm{HT}_{2 \mathrm{~B}}$ receptor antagonist, $\mathrm{AM} 1476$, for its ability to reduce pulmonary and dermal fibrosis in the sclerodermatous 